Original Article

\title{
EXPERIMENTAL EVALUATION OF ANTIDEPRESSANT AND ANTIANXIETY ACTIVITIES OF AQUEOUS LEAF EXTRACTS OF SENNA ALATA (L.) ROXB. USING IN VITRO ANIMAL MODELS
}

\author{
ARCHANA PAMULAPARTHI, VAMSHI RAMANA PRATHAP1, MAHITHA BANALA, RAMA SWAMY NANNA*
}

Plant Biotechnology Research Group, Department of Biotechnology, Kakatiya University, Warangal 506009, TS, India, ${ }^{1}$ Jawaharlal Nehru Technological University, Hyderabad 500085, TS, India

Email: swamynr.dr@gmail.com

Received: 19 Jul 2016, Revised and Accepted: 20 Aug 2016

ABSTRACT

Objective: In the present investigation antidepressant and antianxiety activities of aqueous leaf extracts of Senna alata (200 mg/Kg) were carried out to establish the species as a potent natural antidepressant and anxiolytic drug.

Methods: Antidepressant activity was carried out using forced swim test and tail suspension test. In both these tests, the animals were subjected to external stress that results in alteration of the behavior of animal due to fear.

The antianxiety activity of aqueous leaf extracts of $S$. alata has been studied by the elevated plus-maze test in rats. The mean number of entries and the time spent in the open arm after 45 min of the administration of test drug was noted to determine the antianxiety effect of the test drug.

Results: For antidepressant activity administration of test drug (200 mg/Kg) showed a significant decrease in the time spent by the animal in state of depression in both the assays which clearly indicates that the aqueous leaf extracts of $S$. alata exhibited a strong antidepressant activity similar to that of the control drug (Imipramine).

In the antianxiety activity, administration of aqueous leaf extract (200 mg/Kg) of $S$. alata significantly increased the mean number of entries $(2.25 \pm 0.98)$ in the open arm and the time spent in open arm $(2.23 \pm 0.04)$ compared to the control group. The activity of the extract was slightly greater than standard drug Diazepam.

Conclusion: From the above-presented results, it can be concluded that administration of Senna alata aqueous leaf extracts (200 mg/Kg) showed a considerable decrease in both antidepressant and antianxiety activities in all the test animals and can be used in the replacement of commercially available synthetic drugs in the near future.

Keywords: Antianxiety activity, Antidepressant activity, Aqueous leaf extracts, Senna alata

(C) 2016 The Authors. Published by Innovare Academic Sciences Pvt Ltd. This is an open access article under the CC BY license (http://creativecommons.org/licenses/by/4.0/) DOI: http://dx.doi.org/10.22159/ijcpr.2016v8i4.15280

\section{INTRODUCTION}

Depression is the most common multifacetic disorder of the mood, the symptoms of which may range from very mild condition of mood swings to severe psychotic depression. According to a report by WHO, approximately 450 million people suffer from behavioral disorders (WHO) which account for $12.3 \%$ of the global population and will increase to $15 \%$ by $2020[1,2]$. Depression is identified to be physiological, biologically and symptomatically variable. Although Benzodiazepines are used for treating depression since ancient time, they pose a number of side effects like muscle relaxation, sedation, physical dependence, memory disturbance and interaction with other drugs. Other drugs include norepinephrine reuptake inhibitors like amitriptyline, Tricyclic depressants and selective serotonin reuptake inhibitors (SSRI) like fluoxetine. Hence, there is a need for the development of alternative medications for these disorders. A number of plants are used as herbal medicine for the treatment of depression. They are: Centella asiatica, Hypericum perforatum, Withania Somnifera, Rauwolfia serpentine, Shizandra chinesis, Thea sinensis [3], Cucurbita pepo [4], Hippophae rhamnoides [5], Annona squamosa [6], Ocimum sanctum [7], Cassia occidentalis [8].

The two most widely used animal models for screening antidepressant drugs are forced swim test (FST) and tail suspension test (TST). These are quite sensitive, specific and reliable for the screening of all classes of antidepressants. In both TST and FST, immobility is thought to reflect either behavioral despair or passive behavior i.e. the ability of an animal to cope up with stressful stimuli [8]. FST is widely used due to its ability to screen a broad spectrum of antidepressant drugs. This test is based on the surveillance that animals follow an initial escape-oriented behavior and develop an immobile stance when placed in a cylinder filled with water.
Anxiety is the second most psychological disorder that affects oneeighth of the world population and has been an interesting topic in the research area of psychopharmacology in this decade. Anxiety disorders are also known as panic disorders and usually occur without any warning. Anxiety attacks are usually peak for the first ten minutes and may last up to half an hour. Anxiety can be categorized into six main types each with their specific symptomatic profile. They are generalized anxiety, obsessive-compulsive disorder, panic disorder, phobia, post traumic stress disorder and social anxiety disorder [9].

Treatments offered to anxiety disorders include behavioral therapy or medication or in some cases the combination of two. Behavior therapy includes cognitive behavioral therapy and exposure therapy. Medication includes Benzodiazepines and antidepressants. However, antidepressants used for treating anxiety disorders can be habit forming and cause unwanted side effects like sedation, ataxia, amnesia, muscle relaxation and barbiturate potentiation and tolerance. To avoid such unwanted side effects, use of herbal medicine as anxiolytic drugs has been in practice in different parts of the world. Thus, the herbal medicines offer a better treatment approach with minimal side effects.

EPM method is based on the principle that animals when placed on EPM, exhibits anxiety due to fear of height. Demonstration of anxiety and fear in animals is manifested by a decrease in the motor activity and their preference to remain at safer places. Antianxiety agents such as Benzodiazepines exhibit anxiolytic activity by increasing their motor activity which can be demonstrated by the time spent by an animal in open arms. In search of new therapeutic agents for treating neurological disorders, research on medicinal plants is 
being progressed continuously demonstrating the pharmacological effectiveness of a variety of plant species using various animal models [10]. A number of plants have been investigated for their anxiolytic activity: Cardiospermum halicacabum [9], Zanthoxylum budrunga [11], Dolichandrone falcate [12], Cissus quadrangularis [13], Pulsatilla nigaricus [14], Cassia occidentalis [8] and Byrsocarpus coccineus [15] have been already reported.

The species Senna alata (L.) Roxb. is an ethnomedicinal plant belonging to family Fabaceae. Even though the plant is known to possess a wide range of medicinal properties [16-18], so far no work has been reported on an antidepressant and anxiolytic activities of the species. Hence, the present study has been undertaken to screen the antidepressant and antianxiety activities of aqueous leaf extracts of $S$. alata for establishing it as a potent ethnomedicinal antidepressant and antianxiety drug.

\section{MATERIALS AND METHODS}

\section{Plant material}

Mature leaves of $S$. alata were collected from the medicinal garden, Department of Biotechnology, Kakatiya University, Warangal (TS), India. The samples were authenticated by Prof. N. Rama Swamy, Department of Biotechnology, Kakatiya University, Warangal (TS), India.

\section{Preparation of the extracts}

The leaves were shade dried, powdered using a mechanical blender. The obtained coarse powder was further sieved to obtain a fine powder. 2-3 gms of the leaf powder was macerated overnight using $100 \mathrm{ml}$ distilled water. The extract was then filtered and evaporated to dryness at room temperature to obtain the final yield.

\section{Animals}

Wistar rats and mice of either sex were used for the study. The animals were housed and maintained at $22{ }^{\circ} \mathrm{C}$ under a 12 light $/ 12$ dark cycle with free access to the standard diet and water ad libitum. Efforts were made to minimize animal suffering, and all the experiments were performed based on the guidelines of ethical standards for the investigation in animals. All the experiments were carried out following the approval of Institutional Animal ethical committee (IAEC) and the ethical norms were strictly followed for all the experimental procedures (Ref no. 25 CARE/IAEC-2013).

\section{Drugs and Instruments}

Diazepam (Sigma-Aldrich), Fluoxetine (Sigma-Aldrich), Elevated plus maze were used in the present investigation.

\section{Acute toxicity studies}

Acute toxicity studies were conducted according to OECD guidelines (no. 423). In the present investigation, acute toxicity and gross behavioral studies were carried out in rats after administration of aqueous leaf extract of $S$. alata. The animals fasted for $4 \mathrm{~h}$ before the test. The mice received the test dose of aqueous extract in the form of suspension at a dose of $10 \mathrm{mg} / \mathrm{Kg}$ to $2500 \mathrm{mg} / \mathrm{Kg}$ orally (PO). The behavior (awareness, grooming, irritability, motor activity) and mortality of mice were observed continuously and carefully recorded for $4 \mathrm{~h}$, occasionally followed for next $24 \mathrm{~h}$.

\section{Antidepressant activity}

\section{Tail suspension test (TST)}

For tail suspension test (TST) the technique of Steru et al. [19] was followed. The test animals were moved from the animal house to the laboratory and were allowed to acclimatize for laboratory conditions for 1-2 $\mathrm{h}$. Each mouse was suspended individually from the edge of the table $50 \mathrm{cms}$ from the ground level with the help of an adhesive tape placed approximately $1 \mathrm{~cm}$ from the tip of the tail. Each animal was used only once in the test. The animal under study was acoustically and visually isolated from other animals during the test. The total period of immobility was recorded for $6 \mathrm{~min}$. The animal was considered to be immobile when it did not show any movement, hung passively and remain completely motionless. The total time of immobility was recorded.

\section{Forced swim test}

For Forced Swim Test (FST) the method of Porsolt et al. [20] was followed. It is the most widely used behavioral model for screening antidepressant-like activity in rodents. The experiment was carried out in two trials, the first trial lasts for $15 \mathrm{~min}$, a second trial was performed after $24 \mathrm{~h}$ for 6 min. Animals were moved from the animal house to the laboratory and were allowed to acclimatize the conditions for 1-2 h. Each mice was marked and forced to swim in an open glass chamber $(25 \times 15 \times 25 \mathrm{cms})$ filled with water to a height of $15 \mathrm{cms}$. Water must be deep enough so that the animal cannot touch the bottom with feet/tail. Water was changed for each animal as used water is known to alter the behavioral pattern of the animals. The test was carried for a period of $6 \mathrm{~min}$. The animals showed rapid movements in the water, trying to escape from the water for the first $2 \mathrm{~min}$. The time of immobility was recorded during the next $4 \mathrm{~min}$ of the study.

\section{Antianxiety activity (Elevated plus maze test)}

The animals were kept to fast overnight before the starting of experiment and were selected randomly on the day of the experiment and grouped into 3 of 6 animals each. Group-I received only Dist. $\mathrm{H}_{2} \mathrm{O}$ and served as control. Groups-II and III received standard drug (Diazepam $15 \mathrm{mg} / \mathrm{ml}$ ) and test extract $(200 \mathrm{mg} / \mathrm{Kg}$ body weight of rat) respectively. The antianxiety activity was carried out using the elevated plus maze method.

The elevated plus-maze model is one of the most widely used animal models for testing anxiolytic drugs of new drugs. The elevated plus-maze apparatus consists of two open arms $(35 \times 5 \mathrm{~cm})$, two closed arms ( $30 \times 5 \times 15 \mathrm{~cm})$ that extend from a common central platform $(5 \times 5 \mathrm{~cm})$ and the entire maze elevated $50 \mathrm{~cm}$ from the floor. The animals were placed individually in the center of the maze, head facing towards open arms 45 min after the administration of the test extract. The test was carried out for a period of $5 \mathrm{~min}$. and during this period, the behavioral patterns of the animals such as: a) Number of entries in open and closed arms, b) Average time each animal spends in each arm (average time $=$ total duration in the arm/number of entries, c) Preference of animal to spend in open and closed arm were recorded. The animals were allowed to socialize during the entire experiment. Care was taken to perform the experiment in a sound attenuated environment to minimize external stress and reduce the errors during the entire experiment [21].

\section{RESULTS}

The effect of aqueous leaf extracts of $S$. alata on behavioral patterns for screening anti-depressant like effects has been carried out using TST and FST in mice. The effect of leaf extracts of $S$. alata on animal behavior using FST is shown in fig. 1 . The results showed that aqueous leaf extracts of $S$. alata showed a significant antidepressantlike effect in mice. There was a significant decrease in the time of immobility in both the standard drug $(22.0 \pm 0.26 \mathrm{sec})$ and the test extract $(21.25 \pm 0.12 \mathrm{sec})$ compared to the control group $(62.5 \pm 0.54$ $\mathrm{sec})$. The leaf extracts of $S$. alata $(200 \mathrm{mg} / \mathrm{Kg})$ showed an increased effect compared to the standard drug fluoxetine $(10 \mathrm{mg} / \mathrm{Kg})$.

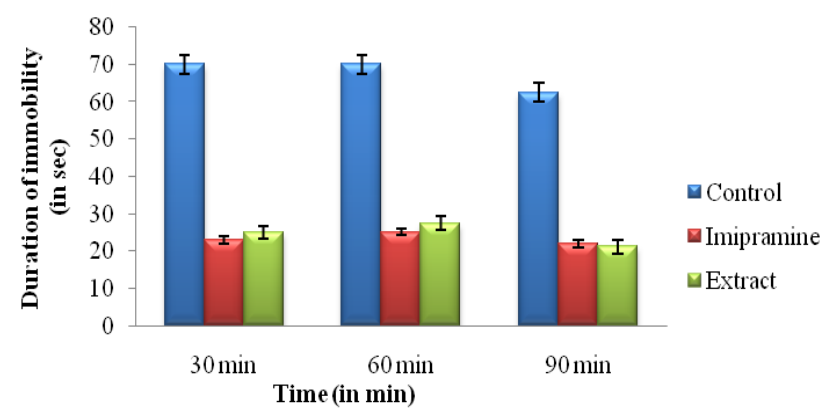

Fig. 1: Effect of aqueous leaf extracts of $S$. alata on antidepressant activity by Forced Swim Test in mice* $n=6$, values are expressed as mean \pm Standard Error $(* p<0.05)$ 
The results on the TST of aqueous leaf extracts of $S$. alata are presented in Fig.2. There was a significant decrease in the immobility of mice in test extract $(59.6 \pm 2.23 \mathrm{sec})$ and a standard drug $(57 \pm 3.5 \mathrm{sec})$ in comparison to the control group $(153.4 \pm 1.97$ sec) after administration of the standard and test extract. These results clearly indicate that aqueous leaf extracts of $S$. alata exhibited a strong antidepressant activity similar to that of the control drug at the end of $2 \mathrm{~h}$ of administration of the standard (Imipramine) and test extract $(200 \mathrm{mg} / \mathrm{Kg})$.

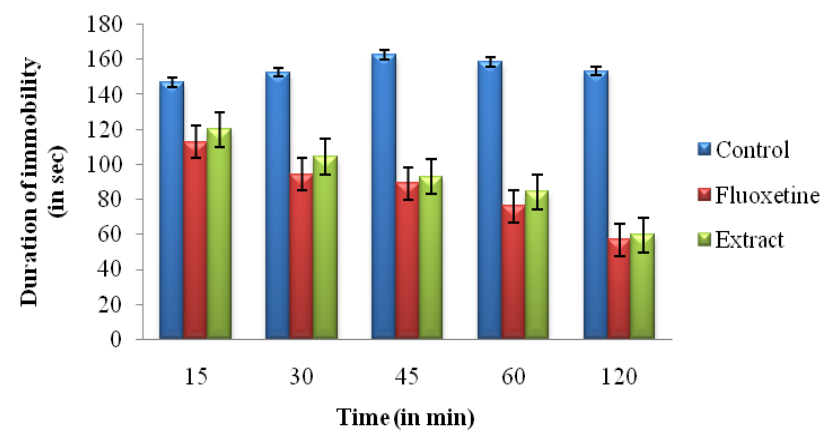

Fig. 2: Effect of aqueous leaf extracts of $S$. alata on antidepressant activity by Tail Suspension Test in mice* $n=6$, values are expressed as mean \pm Standard Error $\left({ }^{*} p<0.05\right)$

Anti-anxiety activity of aqueous leaf extracts of $S$. alata was also studied using EPM method. The mean number of entries and the time spent in the open arm after $45 \mathrm{~min}$ of the administration of test extract are given in fig. 3. Administration of $S$. alata leaf extracts significantly increased the mean number of entries $(2.25 \pm 0.98)$ in the open arm and the time spent in open arm $(2.23 \pm 0.04)$ compared to the control group. The activity of the extract was slightly greater than the test group (fig. 3). Thus, S. alata aqueous leaf extracts exhibited antianxiety activity slightly lower than the standard drug Diazepam.

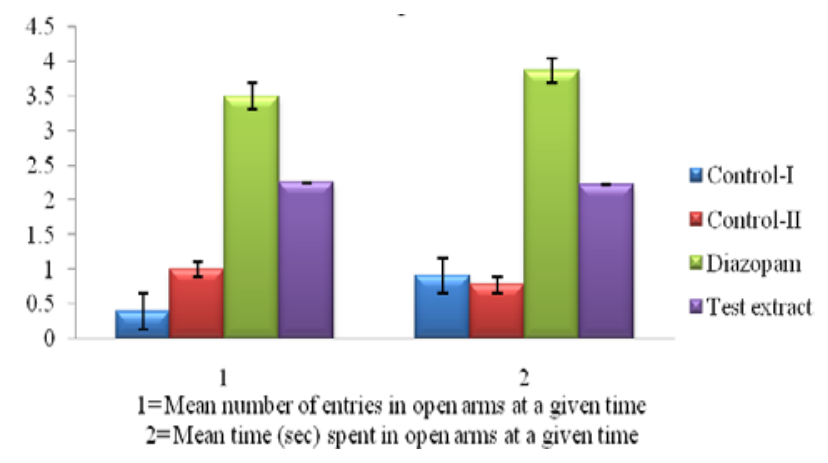

Fig. 3: Anti-anxiety activity of aqueous leaf extracts of $S$. alata using EPM method

$\mathrm{n}=6$; values expressed as mean \pm Standard Error

\section{DISCUSSION}

The results of FST and TST showed that administration of aqueous leaf extracts of $S$. alata $(200 \mathrm{mg} / \mathrm{Kg})$ had a decreased rate of immobility and increased climbing behavior similar to the standard Imipramine in TST and a decrease in immobility and increased swimming behavior similar to the standard drug Fluoxetine in FST compared to the control group. The decrease in the immobility time in both TST and FST depends mainly on the enhancement of 5-hydroxytryptamine (5-HT) and catecholamine neurotransmission [22]. The antidepressant activity of leaf extracts of $S$. alata may be related to their flavonoid content [23]. The leaf of S. alata contains Kaempferol, which seems to appear as conjugated forms in the bloodstream as with other flavonoid glycosides like quercetin [24]. Transportation of these metabolites to the brain via the blood-brain barrier and their effect on CNS has been reported recently [25]. However, further studies are required to identify the phytoconstituents responsible for the antidepressant activity of the species.

Administration of $S$. alata aqueous leaf extracts at a dose of 200 $\mathrm{mg} / \mathrm{Kg}$ body weight decreased the anti-anxiety activity in rodents. The activity was slightly lower than the standard drug Diazepam used. The decrease in the anxiety was noticed by an increase in the number of entries into the open arm and also the time spent in the open arm (table 3). EPM test is highly sensitive and influence both anxiolytic and anxiogenic drugs acting at GABA-benzodiazepine complex [26]. Drugs that act by increasing the mean entries into open arm are considered as anxiolytics and those which act reversibly are considered anxiogenics [27]. The anti-anxiety activity of $S$. alata is due to the presence of flavonoids. Flavonoids have been known to exhibit anti-anxiety activity due to their effect on CNS and Benzodiazepine receptors [28-30]

Our results of the study are in conformity with the observations of previous workers [31] who reported that flavones bind with high affinity to BZD sites of GABAA receptors as flavonoids and diazepam are structurally analogous. A similar mechanism of anxiolytic activity was found in Cassia occidentalis [8].

\section{CONCLUSION}

From the above results, it can be concluded that aqueous leaf extracts of $S$. alata showed a significant antidepressant and antianxiety activities and can be used in replacement of modern, synthetic drugs. The specific active constituents responsible for the antidepressant and anti-anxiety activities are yet to be studied.

\section{ACKNOWLEDGEMENT}

Mrs. Archana Pamulaparthi is grateful to University Grants Commission, New Delhi for providing financial assistance as Project Fellow under the UGC-SAP-DRS-II programme (Ref. No. F. 319/2009 (SAP-II), Dated. 31-3-2009).

\section{CONFLICT OF INTERESTS}

Declare none

\section{REFERENCES}

1. WHO. The World Health Report. Mental health: New understanding new hope. WHO, Geneva; 2001.

2. Reynolds EH. Brain and mind: a challenge for WHO. Lancet 2003;361:1924-5.

3. Mamedov N. Adaptogenic, geriatric, stimulant and antidepressant plants of russian far East. J Cell Mol Biol 2005;4:71-5.

4. Umadevi P, Murugan S, Suganthi SJ, Subakanmani S. Evaluation of antidepressant-like activity of Cucurbita pepo seed extracts in rats. Int J Curr Pharm Res 2011;3:108-13.

5. Batool F, Kamal A, Sattar M, Shah AH, Ahmed SD, Saify ZS, et al. Evaluation of antidepressant-like effects of aqueous extract of sea Buckthorn (Hippophae rhamnoides Linn Ssp. Turkestanica) fruits in experimental models of depression. Pakistan J Bot 2011;43:1595-9.

6. Sharma MC, Sharma S, Kohli DV. Some plant and extracts used in the pharmacologically activity of anxiolytics, antidepressant, analgesic, and anti-inflammatory activity. Digest J Nonmaterial Biostructures 2010;5:223-7.

7. Moinuddin G, Devi K, Satish H, Khajuria DK. Comparative pharmacological evaluation of Ocimum sanctum and imipramine for antidepressant activity. Lat Am J Pharm 2010;30:435-9.

8. Saba Shafeen, Srinath reddy $\mathrm{T}$, Arafath $\mathrm{S}$, Nagarjuna $\mathrm{S}$, Padmanabha reddy Y. Evaluation of the antianxiety and antidepressant activity of Cassia occidentalis leaves. Asian J Pharm Clin Res 2012;5:47-50.

9. Kumar R, Murugananthan G, Nandakumar K, Talwar S. Isolation of anxiolytic principle from ethanolic root extract of Cardiospermum halicacabum. Phytomedicine 2011;18:219-23. 
10. Zhang ZJ. Therapeutic effects of herbal extracts and constituents in animal models of psychiatric disorders. Life Sci 2004;75:1659-99.

11. Bhadoriya BU, Yadov A, Aggarwal N, Jaswal D, Yadov IK, Singh HP, et al. Hypnotic effect of essential oil and methanolic extract of fruits of Zanthoxylum budrunga W. Int J Pharm Tech Res 2009;4:1494-8.

12. Badgujar VB, Surana SJ. Anxiolytic effects of Dolichandrone falcata Seem., Bignoniaceae, stem-bark in elevated plus-maze and marble burying test on mice. Rev Bras Farmacogn 2010;20:773-80.

13. Bum EN, Ngoupaye GT, Talla E, Dimo TG, Nkantchoua CN, Pelanken MM, et al. The anticonvulsant and sedative properties of stems of Cissus quadrangularis in mice. Afr J Pharm Pharmacol 2008;2:42-7.

14. Sandeep Goyal, Suresh Kumar. Anti-anxiety activity studies of various extracts of Pulsatilla nigricans stoerck. Int J Pharm Sci Drug Res 2010;2:291-3.

15. Akindele AJ, Adeyemi 00. Anxiolytic and sedative effects of Byrsocarpus coccineus schum and Thonn. (Connaraceae) extract. Int J Appl Res Nat Prod 2010;3:28-36.

16. Palanichamy S, Nagarajan S, Devasagayam M. Effect of Cassia alata leaf extract on hyperglycemic rats. J Ethnopharmacol 1988;22:81-90.

17. Crockett CO, Guede-Guina F, Pugh D, Vangah-Manda M, Robinson TJ, Olubadewo JO, et al. Cassia alata and the preclinical search for therapeutic agents for the treatment of opportunistic infections in AIDS patients. Cell Mol Biol 1992;38:799-803.

18. Damodaran S, Venkataraman S. A study on the therapeutic efficacy of Cassia alata Linn. Leaf extract against Pityriasis versicolor. J Ehtnopharmacol 1994;42:19-23.

19. Steru L, Chermat R, Thierry B, Simon P. The tail suspension test: a new method for screening antidepressants in mice. Psychopharmacology (Berl.) 1985;85:367-70.

20. Porsolt RD, Bertin A, Jalfre M. Behavioural despair in mice: a primary screening test for antidepressants. Arch Int Pharmacodyn Ther 1977;229:327-36.

21. Kulkarni SK, Reddy DS. Animal behavioral models for testing anti-anxiety agents. Methods Find Exp Clin Pharmacol 1996;18:219-30.
22. Borsini F, Meli A. Is the forced swimming test a suitable model for revealing antidepressant activity? Psychopharmacology 1988;94:147-60.

23. Vikas Gupta, Parveen Bansal, Pawan Kumar, Richa Shri. Anxiolytic and antidepressant activities of different extracts from Citrus paradisi var. Duncan. Asian J Pharm Clin Res 2010;3:98-100.

24. Vimal Kant Sharma, Nagendra Singh Chauhan, Santram Lodhi, AK Singhai. Antidepressant activity of Zizyphus xylopyrus. Int J Phytomed 2009;1:12-7.

25. Youdim KA, Qaiser MZ, Begley DJ, Rice-Evans CA, Abbott NJ. Corrigendum to flavonoid permeability across an in situ model of the blood-brain barrier. Free Radical Biol Med 2004;36:592-604.

26. Jung JW, Ahn WY, Oh HR, Lee BR, Lee KJ, Kim SY, et al. Anxiolytic effect of the aqueous extract of Uncaria rhynchophyll. J Ethnopharmacol 2006;108:193-7.

27. Graeff FG, Guimares FS, De Andrade TG, Deakin JF. The role of 5-HT in stress, anxiety and depression. Pharmacol Biochem Behav 1996;54:129-41.

28. Paladini AC, Marder M, Viola H, Wolfman C, Wasowaki C, Medina JH. Flavonoids and the central nervous system: from forgotten factors to potent anxiolytic compounds. J Pharm Pharmacol 1999;51:519-26.

29. Medina JH, Viola H, Wolfman C, Marder M, Wasowski C, Clavo $\mathrm{D}$, et al. Neuroactive flavonoids: new ligands for the benzodiazepine receptors. Phytomedicine 1997;5:235-43.

30. Wolfman C, Viola H, Paladini A, Dajas F, Medina JH. Possible anxiolytic effects of chrysin, a central benzodiazepine receptor ligand isolated from Passiflora coerulea. Pharmacol Biochem Behav 1994;47:1-4.

31. Bhattacharya SK, Satyan KS. Experimental methods for evaluation of psychotropic agents in rodents: I-anti-anxiety agents. Indian J Exp Biol 1997;35:565-75.

\section{How to cite this article}

- Archana Pamulaparthi, Vamshi Ramana Prathap, Mahitha Banala, Rama Swamy Nanna. Experimental evaluation of antidepressant and antianxiety activities of aqueous leaf extracts of Senna alata (L.) roxb. using in vitro animal models. Int J Curr Pharm Res 2016;8(4):60-63. 